keeping them healthy are more likely to achieve and sustain the technical elements portrayed in the first column. Perhaps the columns that portray the need for leadership and for team investment are a reasonable proxy. In any case, the point of the exercise is to suggest that it may be worth thinking about what kinds of benefits accrue when one adopts each of the standards, what kinds of resources (people, time, and money) are necessary to establish the standards, and how the relative value assigned to each resource expense or benefit would depend upon what constituency is making that judgment. It also suggests that empirical research that takes into account all of these costs, benefits, and stakeholder perspectives would be more helpful than that which only examines a portion of the costs or a portion of the benefits for a single constituency.

Anton J. Kuzel, MD, MHPE; Chair, Department of Family

Medicine, Virginia Commonwealth University, Richmond, VA Elaine M. Skoch, RN, MN, EMBA, CNAA, BC; Vice President for Performance Improvement and Education, TransforMED, Leawood, KS

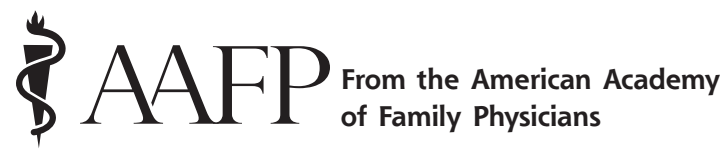

Ann Fam Med 2009;7:86-87. DOI: 10.1370/afm.955

\section{AMA DELEGATES ADOPT AAFP'S JOINT PRINCIPLES OF PATIENT-CENTERED MEDICAL HOME}

After several years of effort, the AAFP and other primary care specialty groups scored a huge win at the 2008 interim meeting of the AMA House of Delegates when the delegates agreed to support the Academy's vision of the patient-centered medical home, or PCMH.

During the meeting, AMA delegates adopted, intact, the "Joint Principles of the Patient-Centered Medical Home," a document that was developed by the AAFP, the American Academy of Pediatrics, the American College of Physicians and the American Osteopathic Association.

The 7 joint principles describe characteristics of the $\mathrm{PCMH}$, including the following:

- Coordination of care to enhance the patientphysician relationship

- A focus on quality and safety

- Enhanced access to care

- A payment structure that recognizes the value of and pays physicians appropriately for coordinated services and care management

According to AAFP President Ted Epperly, MD, of Boise, Idaho, the adoption of the principles is "his- toric" for the Academy because it "brings on board the AMA's support of the joint principles as a health care delivery system that's rooted deeply in primary care for the people of America."

During testimony at a reference committee hearing, Epperly said that the principles exemplify "comprehensive patient-centered health care with deep trusting relationships with a patient's personal physician and his or her practice in which care is integrated, coordinated and focused on the whole person."

"Multiple state, national and international studies have demonstrated that this care will increase the value of health care by increasing quality and lowering cost," Epperly noted.

Dale Moquist, MD, of Houston, Texas, chair of the Academy's delegation to the AMA, said that the delegates' action indicates "where the house of medicine is going to be" on this issue. "When we're testifying about health system reform and the benefits of the $\mathrm{PCMH}$, the AMA can be right beside us," he said.

In all, the delegates acted on several resolutions related to the medical home. One amendment the delegates added was referred to the Board of Trustees for further study. That amendment calls on the AMA, working with all interested specialty societies, to continue to study the PCMH concept, with particular emphasis on ensuring the following:

- The value-added services of the medical home are fully funded by financing mechanisms outside the Medicare Part B physician payment pool, including from private insurance, Medicare Parts A and D, and Medicaid

- Patient access to necessary quality specialty care without a gatekeeper is preserved

- Patients can select any qualified physician practice as their medical home

- The house of medicine is unified on this issue

\section{Primary Care Training}

The AMA House of Delegates also voted to support several measures designed to encourage physicians and physicians-in-training to choose careers in primary care. The measures included calls to enhance payment for primary care physician services and decrease debt loads.

The AMA agreed to advocate creation of various programs to encourage physicians to practice in underserved areas, including the permanent reauthorization and expansion of the Conrad State $30 \mathrm{~J}-1$ visa waiver program.

"We feel we won a trifecta," said Moquist. "We got the adoption of the patient-centered medical home. We got the adoption of the (AMA Council on Medical Education report recommendations on) primary care as a medical career choice. And we got the actions to 
promote physicians to practice in underserved areas," he said, referring to another CME council report.

\section{Barriers to Primary Care}

Noting that patients' access to care is "negatively impacted" by a shortage and maldistribution of primary care physicians, the medical education council report on barriers to primary care directs the AMA, in collaboration with primary care specialty organizations, to advocate the adoption of recommendations from the AMA/Specialty Society Relative Value Scale Update Committee that address payment for evaluation and management, or E/M, services and coverage of services related to care coordination. The report also directs the AMA to work to ensure that private payers recognize the value of E/M services.

The delegates directed the AMA to study matters related to new models of providing primary care services, such as the medical home. Topics for study include the following:

- The impact of these models on primary care physicians' work-life balance and satisfaction

- The growth and expansion of new models in the public and private sectors

- The availability of expanded public- and privatesector funding at national and local levels to support implementation of new models

- The impact of these models on primary care physician compensation

Furthermore, said the delegates, the AMA should support existing programs and advocate the establishment of new programs that decrease the debt load of physicians who choose primary care.

Barbara Bein AAFP News Now

From the American Board of Family Medicine

Ann Fam Med 2009;7:87-89. DOI: 10.1370/afm.952.

\section{PISACANO SCHOLARS}

The Pisacano Leadership Foundation, the philanthropic arm of the American Board of Family Medicine (ABFM), recently selected its 2008 Pisacano Scholars.

These 5 medical students follow in the footsteps of 66 scholar alumni who are practicing physicians and 15 current scholars who are enrolled in family medicine residency programs across the country. The Pisacano Leadership Foundation was created in 1990 by the ABFM in tribute to its founder and first executive director, Nicholas J. Pisacano, MD (1924-1990). Each Pisacano Scholar has demonstrated the highest level of leadership, academic achievement, communication skills, community service, and character and integrity.

Parker Duncan, a 2008 Pisacano Scholar, is a 4thyear medical student at the University of CaliforniaIrvine School of Medicine (UCI). Parker graduated from Duke University with a Bachelor of Arts in Political Science on a Naval ROTC scholarship. He subsequently served 4 years as a junior officer on the USS Nimitz (CVN-68). He was awarded the "Top Snipe" Award from the Naval Engineers' School, United States Army. Parker just recently completed his MPH at California State University.

As a medical student, Parker has received a number of awards, including the Service Award from the Associated Medical Students Government. He was also inducted into the Gold Humanism Honor Society. While attending his first AMSA Conference, Parker learned of SB 840, or the California Health Insurance Reliability Act. Soon after Parker became co-president of the AMSA Chapter at UCI, organizing the school's first meeting and election of officers. Parker co-created and organized Lobby Day with a UCSF medical student, which included a rally and legislative visits in support of SB 840 .

Parker is a member of the Board of Directors for the California Physicians Alliance (CAPA); he and his co-creator for Lobby Day are the first ever student board members. He and his UCSF counterpart served as coordinators for Lobby Day 2008, which had almost 3 times the number of attendees as the year before.

Parker's vision of his future career in family medicine involves a comprehensive, integrative health outpatient clinic - a full-service, outpatient center that supports proactive health. He also envisions partner clinics in Mexico or other Latin American countries.

Lara Jirmanus, a 2008 Pisacano Scholar, is a 4thyear medical student at the University of Massachusetts Medical School (UMass). Lara graduated cum laude from Harvard University with a Bachelor of Arts in Biophysics. She was awarded the Harvard College Scholarship for Academic Achievement each of her 4 years there.

After college, Lara interned with the HIV/AIDS Department of the World Health Organization and with the Women's Humanitarian Organization in Beirut, Lebanon, in a refugee camp. At UMass, Lara helped organize relief efforts after Hurricane Katrina, planning a talent show and art auctions to raise money for hurricane victims. Lara's classmates recently awarded her with the Student Body Committee Leadership Award for her service on the national coordinating committee of the UMass Chapter of Universities 